\title{
A new method for estimating aerosol mass flux in the urban surface layer using LAS technology
}

\author{
Renmin Yuan ${ }^{1}$, Tao Luo ${ }^{1}$, Jianning Sun ${ }^{2}$, Hao Liu ${ }^{1}$, Yunfei Fu ${ }^{1}$, and Zhien Wang ${ }^{3}$ \\ ${ }^{1}$ School of Earth and Space Sciences, University of Science and Technology of China, Anhui, 230026, China \\ ${ }^{2}$ School of Atmospheric Sciences, Nanjing University, Jiangsu, 210023, China \\ ${ }^{3}$ Department of Atmospheric Science, University of Wyoming, Laramie, Wyoming, WY 82070, USA \\ Correspondence to: Renmin Yuan (rmyuan@ustc.edu.cn) and Tao Luo (luotao@ustc.edu.cn)
}

Received: 11 October 2015 - Published in Atmos. Meas. Tech. Discuss.: 19 January 2016

Revised: 10 April 2016 - Accepted: 22 April 2016 - Published: 29 April 2016

\begin{abstract}
Atmospheric aerosol greatly influences human health and the natural environment, as well as the weather and climate system. Therefore, atmospheric aerosol has attracted significant attention from society. Despite consistent research efforts, there are still uncertainties in understanding its effects due to poor knowledge about aerosol vertical transport caused by the limited measurement capabilities of aerosol mass vertical transport flux. In this paper, a new method for measuring atmospheric aerosol vertical transport flux is developed based on the similarity theory of surface layer, the theory of light propagation in a turbulent atmosphere, and the observations and studies of the atmospheric equivalent refractive index (AERI). The results show that aerosol mass flux can be linked to the real and imaginary parts of the atmospheric equivalent refractive index structure parameter (AERISP) and the ratio of aerosol mass concentration to the imaginary part of the AERI. The real and imaginary parts of the AERISP can be measured based on the lightpropagation theory. The ratio of the aerosol mass concentration to the imaginary part of the AERI can be measured based on the measurements of aerosol mass concentration and visibility. The observational results show that aerosol vertical transport flux varies diurnally and is related to the aerosol spatial distribution. The maximum aerosol flux during the experimental period in Hefei City was $0.017 \mathrm{mg} \mathrm{m}^{-2} \mathrm{~s}^{-1}$, and the mean value was $0.004 \mathrm{mg} \mathrm{m}^{-2} \mathrm{~s}^{-1}$. The new method offers an effective way to study aerosol vertical transport in complex environments.
\end{abstract}

\section{Introduction}

The impacts of atmospheric aerosols on climate change have drawn significant attention from society (IPCC, 2014). To better understand the aerosols, there are many conventional and routine measurements, such as measuring the concentration of aerosol particles for environmental protection (Chang and Lee, 2007; Cruz et al., 2015), building observation networks of ground-based and remote sensing for tropospheric aerosol properties and radiative forcing (to measure the optical depth, concentration, and physical and chemical properties of aerosols) $s$ (Cruz et al., 2015; Dubovik et al., 2002), and performing some special scientific experiments (Li et al., 2015; Wood et al., 2013). Over the past 20 years, progress has been made to measure the concentration, size distribution, and physical and chemical properties of aerosols (Moosmueller et al., 2009). However, there are still large uncertainties in quantifying the effects of atmospheric aerosols on Earth's energy budget by scattering and absorbing radiation and by modifying the amounts and microphysical and radiative properties in clouds (Myhre et al., 2009; IPCC, 2007, 2014). Therefore, more representative and accurate data are required (Chin et al., 2009; IPCC, 2014). The climatic effect of aerosol was also extensively studied through numerical model simulations, which must also be verified by more directly measured aerosol data, especially aerosol emissions from the surface (Myhre et al., 2009). The forecast for urban environmental pollution must also directly measure the aerosol source emission (Wu et al., 2012).

So far, we can provide accurate physical and chemical aerosol properties, such as concentration, shape, size, opti- 
cal properties and chemical components, especially with in situ sampling instruments (Nakayama et al., 2014; Wang et al., 2015). However, other key aerosol processes, such as emission intensity and vertical transport, which are required for simulations of large-scale atmospheric chemical transport and forecasting local and regional air quality, are poorly measured. Studies (Seinfeld and Pandis, 2006; Bond et al., 2004) have shown that model simulations on the impacts of aerosols on the environment and climate require aerosol source emission and transport data, especially the emission of anthropogenic aerosols primarily arising from a variety of combustion sources (Li et al., 2009).

There are a few methods to provide aerosol emission data. One method is to perform statistical analyses of the aerosol parameters and estimate the aerosol flux based on data from sources such as the statistical yearbooks by governments, including activities of power generation (Kondratyev et al., 2006; Chin et al., 2009; Zhao et al., 2012). Another method is to estimate aerosol flux using the method of estimating gas flux (Stull, 1988), such as the Bowen ratio method (Lighthart and Shaffer, 1994). However, there are still large uncertainties in estimating the upward aerosol flux that is transported from the ground in these two methods (Bond et al., 2004; Kanakidou et al., 2005).

In recent years, with the wide use of instruments for measuring aerosol particle number concentrations (such as the GP-WCPC3787 particle counter produced by TSI), it is possible to measure the vertical transport flux of the aerosol particle number density with the eddy-covariance (EC) method. The vertical transport flux of aerosol particle number density $\left(F_{\mathrm{p}}\right)$ is expressed as the cross-correlation between vertical wind velocity $\left(w^{\prime}\right)$ and aerosol particle number density $\left(N^{\prime}\right)$ (Ripamonti et al., 2013). Fluctuations in the vertical velocity and aerosol particle number density must be measured simultaneously at high temporal resolutions to provide an aerosol particle number flux.

Measurements of aerosol vertical transport flux using the EC method have been carried out recently in many cities including Stockholm (Vogt et al., 2011b), Helsinki (Ripamonti et al., 2013), Lecce (Samain et al., 2012), Munster (Pauwels et al., 2008), and London (Harrison et al., 2012). The EC method has also been used to determine the aerosol particle number concentration flux at other sites, such as sea-salt aerosol concentration flux measurements in Northern Europe (Brooks et al., 2009; Sproson et al., 2013).

These measurement capabilities have provided new insights about atmospheric aerosols, such as a strong correlation between atmospheric aerosol particle flux and traffic flow rate in urban areas (Järvi et al., 2009), characteristics of sea-salt aerosol transportation, and the physicalchemical properties of aerosols (Nemitz et al., 2009). The measurements were mostly taken in cities that have key anthropogenic sources. Urban measurements are easy to obtain with high reliability and can be used as routine model inputs. Although an urban aerosol particle number flux has been measured with the EC method, the results represent an aerosol particle number flux only at a single point. However, the underlying surface in urban areas is very complex, with a large horizontal inhomogeneity, and single-point measurements are not very representative. Therefore, the development of a new measurement system to provide an aerosol flux representing a larger spatial region is important. Furthermore, the parameter measured by the EC theory is the aerosol particle number flux, which is often dominated by a high concentration of smaller particles. However, for many applications, the aerosol mass flux is more important.

The sensible heat flux measurements made by the EC method are mature and widely used (Lee, 2004). However, the sensible heat flux can also be measured by a general large aperture scintillometer (LAS) based on the similarity theory and the light-propagation theory (Zeweldi et al., 2010). This inspired us to explore the potential to measure aerosol flux using the similarity theory and the light-propagation theory with a LAS.

We recently measured the imaginary part of the AERISP based on the light-propagation theory (Yuan et al., 2015). The results showed that the imaginary parts of the AERISP were related to the turbulent transport process and the spatial distribution characteristics of aerosols. The atmospheric equivalent refractive index (AERI) depends on scattering and absorption of aerosol particles (Barrera et al., 2007; Calhoun et al., 2010; van de Hulst, 1957), and should be related to the mass concentration of aerosol particles. Therefore, similar to the fact that the temperature structure parameter can reflect the sensible heat flux, the imaginary part of the AERISP may reflect the aerosol mass flux. This paper will present a new method based on this consideration and present the results from field measurements.

Section 2 provides the theory and methods for the aerosol mass transport flux measurement. The experiment is introduced in Sect. 3. Section 4 presents the field observational results, and a conclusion and discussion are presented in the final section.

\section{Theory and method}

\subsection{Theory of aerosol mass flux measurement}

Experiments showed that small aerosol particles followed the same laws of turbulent motion as air molecules, that is, the fluctuation of the particle concentration followed the " $-5 / 3$ " power law under unstable atmospheric stratification, and the concentration-velocity co-spectra for particle number flux followed the "-4/3" power law (Mårtensson et al., 2006; Vogt et al., 2011a; Kaimal et al., 1972). Therefore, the distribution of small particles can be regarded as a passive conservative quantity, just like the temperature field. Then, at the separation $(r)$ of the order of inertial subrange scales, the aerosol mass concentration (denoted as $M_{\mathrm{a}}$ ) structure function $\left(D_{\mathrm{M}}(\boldsymbol{r})\right)$ in a locally isotropic field follows the " $2 / 3$ law" 
(Wyngaard, 2010) and can be expressed as

$D_{\mathrm{M}}(\boldsymbol{r})=\overline{\left[M_{\mathrm{a}}(\boldsymbol{x})-M_{\mathrm{a}}(\boldsymbol{x}+\boldsymbol{r})\right]^{2}}=C_{\mathrm{M}}^{2} r^{2 / 3}$,

where $\boldsymbol{r}$ is the separation vector, $\boldsymbol{x}$ is the position vector, $C_{\mathrm{M}}^{2}$ is the aerosol mass concentration structure parameter, and the overbar in Eq. (1) indicates the spatial average. Based on field experiments (Mårtensson et al., 2006; Vogt et al., 2011a), the mass concentration in the surface layer will follow the similarity theory (Obukhov, 1971; Wyngaard et al., 1971):

$\frac{C_{\mathrm{M}}^{2} z^{2 / 3}}{M_{*}^{2}}=\eta\left(\frac{z}{L}\right)$,

where $z$ is the effective height above the reference plane (Evans and De Bruin, 2011; Hartogensis et al., 2003), $L$ is the Monin-Obukhov (M-O) length and is defined as $L=\frac{\bar{T} u_{*}^{2}}{\kappa g T_{*}}=$ $-\frac{\bar{T} u_{*}^{3}}{\kappa g \bar{\theta}^{\prime} w^{\prime}}$ (Stull, 1988), $\bar{T}$ is the average temperature, $u_{*}$ is the friction velocity, $T_{*}$ is the surface-layer temperature scale, $\kappa$ is the Karman constant, which is $0.4, g$ is gravity acceleration, and $\overline{w^{\prime} \theta^{\prime}}$ is the cross-correlation between the vertical turbulent velocity and temperature fluctuation. $M_{*}$ can be regarded as the atmospheric aerosol mass concentration scale in the surface layer, which is similar to the surfacelayer temperature scale. The stability function $\left(\eta\left(\frac{z}{L}\right)\right)$ can be expressed as in the following form depending on the stability condition (DeBruin et al., 1995):

$\eta\left(\frac{z}{L}\right)=4.9\left(1+9\left|\frac{z}{L}\right|\right)^{-2 / 3}$

for unstable conditions $(z / L<0)$, and

$\eta\left(\frac{z}{L}\right)=4.9\left(1+2.75\left|\frac{z}{L}\right|\right)$

for stable conditions $(z / L>=0)$ (Wyngaard et al., 1971).

Equation (2) has the same form as the similarity theory (Obukhov, 1971; Wyngaard et al., 1971) for the temperature structure parameter $\left(C_{\mathrm{T}}^{2}\right)$ with the condition of free convection in the surface layer:

$\frac{C_{\mathrm{T}}^{2} z^{2 / 3}}{T_{*}^{2}}=\eta\left(\frac{z}{L}\right)$.

Similar to the expression of heat flux $\left(Q=\overline{\theta^{\prime} w^{\prime}}=\right.$ $-u_{*} T_{*}$ ) (Stull, 1988), the aerosol mass flux can be expressed as $F_{\mathrm{a}}=-u_{*} M_{*}$, which is used to obtain aerosol flux from measurements. From Eqs. (2) and (5), we have

$F_{\mathrm{a}}=-\left(\frac{C_{\mathrm{M}}^{2}}{C_{\mathrm{T}}^{2}}\right)^{1 / 2} u_{*} T_{*}$.

When the free convection approximation $\left(-\frac{z}{L} \gg 1\right)$ is assumed, based on the similarity theory (Wyngaard et al., 1971) and the definition of M-O length, we can obtain

$F_{\mathrm{a}}=a\left(\frac{g}{\bar{T}}\right)^{1 / 2}\left(C_{\mathrm{M}}^{2}\right)^{1 / 2}\left(C_{\mathrm{T}}^{2}\right)^{1 / 4} z$

where the coefficient $a$ can be set as 0.567 (DeBruin et al., 1995; Lagouarde et al., 2006). Equations (6)-(7) are the theoretical basis for the aerosol mass flux measurements.

\subsection{Measurement methods}

The variables $C_{\mathrm{T}}^{2}$ and $C_{\mathrm{M}}^{2}$ in Eqs. (6)-(7) can be derived from the real and imaginary parts of the AERISP as $C_{n, \mathrm{Re}}^{2}$ and $C_{n, \text { Im }}^{2}$, respectively (Yuan et al., 2015).

The real part of the AERI $\left(n_{\mathrm{Re}}\right)$ for a visible optical wave is (Hill, 1978):

$n_{\mathrm{Re}}=77.6 \times 10^{-6} \times\left(1+\frac{7.52 \times 10^{-3}}{\lambda^{2}}\right) \frac{\bar{P}}{\bar{T}}$,

where $\bar{P}$ is the atmospheric pressure $(\mathrm{hPa})$ and $\lambda$ is the work wave length $(\mu \mathrm{m})$. Then, we have

$C_{\mathrm{T}}^{2}=R_{\mathrm{TN}}^{2} C_{n, \mathrm{Re}}^{2}$,

where the coefficient $R_{\mathrm{TN}}=1.29 \times 10^{4} \times(1+$ $\left.\frac{7.52 \times 10^{-3}}{\lambda^{2}}\right)^{-1} \frac{\bar{T}^{2}}{\bar{P}}$.

The gases and aerosol particles in the atmosphere as a whole can be regarded as an equivalent medium, and its equivalent refractive index is called the atmospheric equivalent refractive index (AERI). The AERI consists of the real part $\left(n_{\mathrm{Re}}\right)$ and the imaginary part $\left(n_{\mathrm{Im}}\right)$. For the atmosphere transparent band, $n_{\mathrm{Re}}$ mainly depends on atmospheric temperature, and $n_{\text {Im }}$ depends on aerosol extinction (details are given in the Appendix A). For a given wavelength ( $\lambda$ ) (usually constant in an experiment), $n_{\mathrm{Im}}$ is related to the chemical composition, concentration and size distribution of aerosol particles. From the results of the numerical calculation (Jennings et al., 1978, 1979), even if the concentration of the aerosols is constant, the aerosol extinction changes with the refractive index and size distribution of the aerosols. Therefore, we can conclude that the AERI changes with the refractive index and size distribution of aerosols even if the concentration of aerosols is constant. In other words, a simple relationship, or a one-to-one corresponding relationship, does not exist between $n_{\mathrm{Im}}$ and the mass concentration of aerosols $\left(M_{\mathrm{a}}\right)$. However, experimental results (Cachorro and Tanre, 1997) showed that $n_{\mathrm{Im}}$ (or $\beta_{\mathrm{e}}$, the aerosol extinction coefficient) and $M_{\mathrm{a}}$ have a good linear relationship (see Sect. 4.2). We can define a parameter as the ratio of the aerosol mass concentration $M_{\mathrm{a}}$ to the imaginary part of the AERI $\left(n_{\mathrm{Im}}\right)$ :

$R_{\mathrm{MN}}=\frac{M_{\mathrm{a}}}{n_{\mathrm{Im}}}$.

Theoretical analysis has shown that $R_{\mathrm{MN}}$ is related to the aerosol particle refractive index, mass density of the aerosol particles, and particle size distribution. For near-surface aerosols at a given location, we can treat $R_{\mathrm{MN}}$ as a constant because of the relatively small variations in particle size and aerosol refractive index (Dubovik et al., 2002). Then, there is a simple linear relationship between $C_{\mathrm{M}}^{2}$ and $C_{n, \mathrm{Im}}^{2}$. Based on Eq. (10), the relationship is

$C_{\mathrm{M}}^{2}=R_{\mathrm{MN}}^{2} C_{n, \mathrm{Im}}^{2}$. 
To obtain $R_{\mathrm{MN}}$, measurements must be taken for $M_{\mathrm{a}}$ and $n_{\mathrm{Im}}$. $M_{\mathrm{a}}$ is easily available from regular particle air quality measurements with several standard instruments (Gebicki and Szymanska, 2012; Wang et al., 2012), such as the beta ray attenuation method. Based on the definition of the aerosol extinction coefficient $\left(\beta_{\mathrm{e}}\right)$ (Liou, 2002; van de Hulst, 1957), $n_{\mathrm{Im}}$ can be obtained from the relationship between $n_{\mathrm{Im}}$ and the aerosol extinction coefficient $\left(\beta_{\mathrm{e}}\right)$ (seen in the Appendix A):

$n_{\mathrm{Im}}=\frac{\lambda \beta_{\mathrm{e}}}{4 \pi}$,

where $\beta_{\mathrm{e}}$ can be obtained from the visibility measurements (Qiu et al., 2004):

$\beta_{\mathrm{e}}=\frac{3.912}{L_{\mathrm{V}}}\left(\frac{0.55 \times 10^{-6}}{\lambda}\right)^{\alpha}$,

where $\alpha$ is the Angstrom exponent and is usually set to $1, \lambda$ is the work wave length $(\mu \mathrm{m})$ for the visibility measurements.

Based on the relationship between $\beta_{\mathrm{e}}$ and $n_{\mathrm{Im}}$ in Eqs. (12)(13), we obtain

$n_{\mathrm{Im}}=\frac{0.55 e-6}{4 \pi} \cdot \frac{3.912}{L_{\mathrm{V}}}$,

where the unit of visibility $\left(L_{\mathrm{V}}\right)$ is $m$. Thus, we can obtain $n_{\text {Im }}$ from visibility measurements.

$C_{n, \mathrm{Re}}^{2}$ and $C_{n, \mathrm{Im}}^{2}$ can be measured by a specially made LAS (Yuan et al., 2015). After a spherical wave propagates over a distance in a turbulent atmosphere, the light intensity on the receiving end will fluctuate. When the attenuation caused by scattering and absorption along the propagation path is very weak, light intensity fluctuation depends on the fluctuation of the real part of the AERI along the propagation path. When the attenuation caused by scattering and absorption along the propagation path is relatively strong, the light intensity fluctuation is also related to the fluctuation of the imaginary part of the AERI along the propagation path. With the spectral analysis method, the LAS light intensity fluctuations can be separated into the contributions of the real and imaginary parts of the AERI. The contribution of the real part of the AERI corresponds to the high frequencies, whereas the contribution of the imaginary part of the AERI corresponds to the low frequencies, suggesting that the variances resulting from the real and imaginary parts are independent. Therefore, the light intensity variances induced by the real and imaginary parts can be detected separately at high frequencies and low frequencies from the LAS measurements (Yuan et al., 2015). The real part of the AERISP $\left(C_{n, \mathrm{Re}}^{2}\right)$ can be calculated from the variance of the high-frequency part, and the imaginary part of the AERISP $\left(C_{n, \mathrm{Im}}^{2}\right)$ can be calculated from the variance of the low-frequency part. According to the relationship between the temperature and the real part of the AERI, $C_{\mathrm{T}}^{2}$ can be obtained from the real part of the AERISP $\left(C_{n, \mathrm{Re}}^{2}\right)$. Similarly, $C_{\mathrm{M}}^{2}$ can be obtained from the imaginary part of the AERISP $\left(C_{n, \text { Im }}^{2}\right)$. Although the LAS was widely used to measure the sensible heat flux along the propagation path, only the high-frequency part of the light intensity fluctuation could be provided, and the low-frequency light intensity was often discarded (Solignac et al., 2012). Thus, a specially designed LAS (see details in Sect. 3) was needed (Yuan et al., 2015).

To apply Eq. (6) to obtain the aerosol mass flux, the friction velocity $\left(u_{*}\right)$ and the surface-layer temperature scale $\left(T_{*}\right)$ in Eq. (6) were needed, which can be determined from the wind speed $(U(z))$ and $C_{\mathrm{T}}^{2}$ measurements. Based on the surface similarity theory for wind speed, the friction velocity $\left(u_{*}\right)$ can be expressed as

$$
u_{*}=\frac{\kappa U(z)}{\ln \frac{z}{z_{0}}-3 \ln \left(\frac{1+\sqrt{1+3.6|\mathrm{z} / \mathrm{L}|^{2 / 3}}}{1+\sqrt{1+3.6\left|\mathrm{z}_{0} / \mathrm{L}\right|^{2 / 3}}}\right)}
$$

for unstable conditions $(z / L<0)$ (Wilson, 2001), where $z_{0}$ is the roughness length, and

$$
u_{*}=\frac{\kappa U(z)}{\ln \left(\frac{z}{z_{0}}\right)+4.7\left(\frac{z}{L}\right)}
$$

for stable conditions $(z / L>0)$ (Stull, 1988).

The variables $u_{*}$ and $T_{*}$ can be calculated iteratively using Eqs. (3), (4), (5), (15), and (16) from $C_{\mathrm{T}}^{2}$ and wind velocity $(U(z))$ at an effective height $(z)$ (Samain et al., 2012). The variables $u_{*}$ and $T_{*}$ can also be calculated as $u_{*}^{2}=$ $\sqrt{\left(\overline{u^{\prime} w^{\prime}}\right)^{2}+\left(\overline{v^{\prime} w^{\prime}}\right)^{2}}$ and $T_{*}=-\overline{\theta^{\prime} w^{\prime}} / u_{*}$ (Stull, 1988). The cross-correlations between the turbulent velocity components $\left(\overline{u^{\prime} w^{\prime}}, \overline{v^{\prime} w^{\prime}}\right.$ and $\left.\overline{u^{\prime} v^{\prime}}\right)$ or between the turbulent velocity components and the temperature fluctuation $\left(\overline{u^{\prime} T^{\prime}}, \overline{v^{\prime} T^{\prime}}\right.$ and $\left.\overline{w^{\prime} T^{\prime}}\right)$ can be calculated from the data collected from a 3-D sonic anemometer $\left(u^{\prime}, v^{\prime}, w^{\prime}\right.$ and $\left.T^{\prime}\right)$. Then, the MoninObukhov (M-O) length $(L)$ can be calculated based on the definition of M-O length (Stull, 1988; Wyngaard, 2010).

Although $u_{*}$ and $T_{*}$ can be obtained for the aerosol mass flux from measurements, Eq. (7) is more attractive because fewer variables are needed if a large error is not introduced by the free convection approximation. According to Kohsiek (1982), Eq. (7) can be applied down to $-z / L>0.02$. In Eq. (7), $F_{\mathrm{a}}$ is proportional to the product of the square root of $C_{n, \mathrm{Im}}^{2}$ and one-quarter of the power of $C_{\mathrm{T}}^{2}$. That is, the aerosol mass flux is related to both the spatial distribution of the aerosol and the turbulence strength. It can also be seen from Eq. (7) that the aerosol mass flux is related to $R_{\mathrm{MN}}$, which is related to the aerosol type and size distribution. Based on the surface similarity theory, $C_{n, \mathrm{Im}}^{2}$ and $C_{\mathrm{T}}^{2}$ are both proportional to the four-thirds power of the effective height $(z)$, so the aerosol mass flux does not vary with height, but the effective height $(z)$ must still be carefully estimated. The method to estimate the effective height $(z)$ is the same as the method for estimating the sensible heat flux with a LAS (Evans and De Bruin, 2011). 


\section{Measurement and data processing}

Experiments were conducted at two sites, shown as the shadow part and point $P$ in the southern part of Hefei City in Fig. 1a. The shadow part in Fig. 1a is the campus of USTC (the University of Science and Technology of China), which was the location for the light-propagation experiments, and point $P$ represents the location for determining the aerosol mass concentration $\left(M_{\mathrm{a}}\right)$ and visibility $\left(L_{\mathrm{V}}\right)$.

Figure $1 \mathrm{~b}$ displays the measurement site on the USTC campus corresponding to the shadow part in Fig. 1a. The measurement site is a typical urban surface in the area. The roads near the campus often have heavy traffic. One road to the west of campus is a viaduct, and one road to the north of campus has eight lanes. The two roads are two arterial highways in Hefei City. There are trees and four-story buildings across most areas of the campus, and the mean height is approximately $1 \mathrm{~m}$; therefore, a plane at a height of $15 \mathrm{~m}$ can be the reference plane. The roughness $\left(z_{0}\right)$ is derived from Chen's method (Chen et al., 1993). Eventually, average values of $z_{0}=0.96 \mathrm{~m}$ were used for the measurement site.

The LAS measurements were performed between one building with a height of $55 \mathrm{~m}$ (symbol A in Fig. 1b) and another with a height of $62 \mathrm{~m}$ (symbol B in Fig. 1b) The distance between the two buildings was $960 \mathrm{~m}$. The transmitter of the LAS was placed at building $\mathrm{A}$, and the receiver was placed at building $\mathrm{B}$. The propagation path was along the south-north direction. The experiments were conducted on the 10th floor of the two buildings, $18 \mathrm{~m}$ above the reference plane. For a typical LAS measurement, the measurement height is a very important physical quantity and should be carefully measured and calibrated (Evans and De Bruin, 2011; Hartogensis et al., 2003). For our measurement of aerosol mass flux, the effective height is also a very important parameter and can be calculated as $18.0 \mathrm{~m}$. The signal measured by the LAS to retrieve the heat flux had a relatively large weight in the middle of the propagating path (Wang et al., 1978). The sonic anemometer measurements showed that the turbulence characteristics over the campus did not exhibit significant inhomogeneity. The measurement height of $18 \mathrm{~m}$ above the reference plane was high enough to meet the isotropy assumption (Mårtensson et al., 2006).

The LAS was built at USTC based on an instrument concept initially developed by Wang et al. (1978), and the light wavelength was $0.625 \mu \mathrm{m}$. Our LAS was very similar to the LAS used to measure the surface-layer sensible heat flux (Moene et al., 2009; Kleissl et al., 2008). The LAS for measuring surface-layer sensible heat flux often discards the electronic component with a frequency lower than $0.2 \mathrm{~Hz}$ (Kipp and Zonen, 2007). The bandwidth of the amplifier for our LAS receiver ranged from 0.001 to $250 \mathrm{~Hz}$, and the output signal was sampled at a frequency of $500 \mathrm{~Hz}$. The unprocessed raw data files were saved in 20 min intervals. The diameters of transmitting and receiving apertures of our LAS were both $0.18 \mathrm{~m}$. The emitted light converged on a transmit

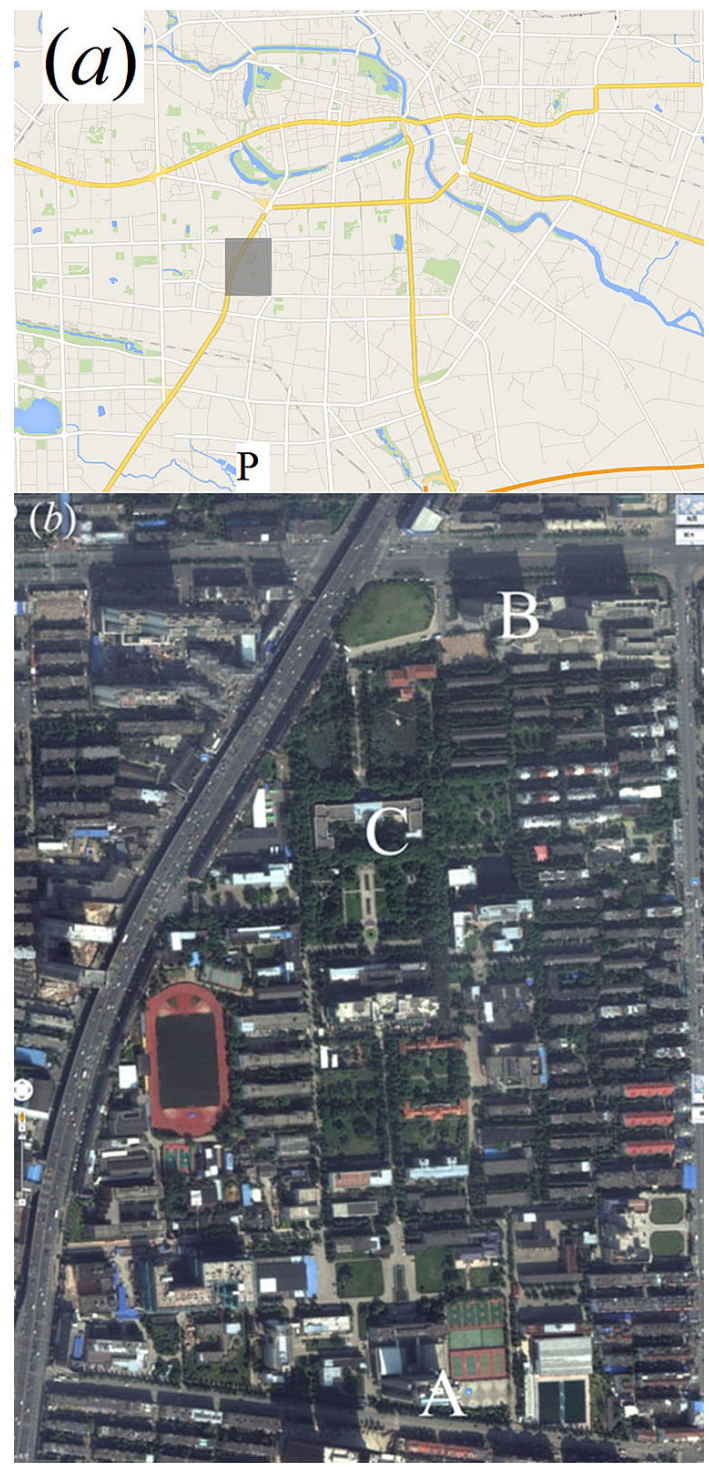

Figure 1. Photographs of the measurement site. (a) Map of Hefei City and (b) expanded view of the measurement site on the USTC campus, which is marked as the shaded rectangle in (a). Point $P$ in (a) indicates the site from which visibility and aerosol mass concentration measurements were obtained. Points A and B in (b) show the locations of the transmitter and receiver, respectively. Point $C$ in (b) marks the meteorological tower position. There are four heavy traffic roads surrounding the measurement site. Figure 1a and $b$ (c) Google.

lens so as to reduce the divergence angle and then propagated over $960 \mathrm{~m}$ to the receiver. A photodetector was placed at the focus of the receiving lens, which transfers light intensities to electrical signals. The electrical signals were demodulated and amplified by an amplifier. More details about our LAS can be found in the previous paper of Yuan et al. (2015).

A meteorology tower was installed on the roof of a building (symbol C in Fig. 1b). The tower was close to the light 


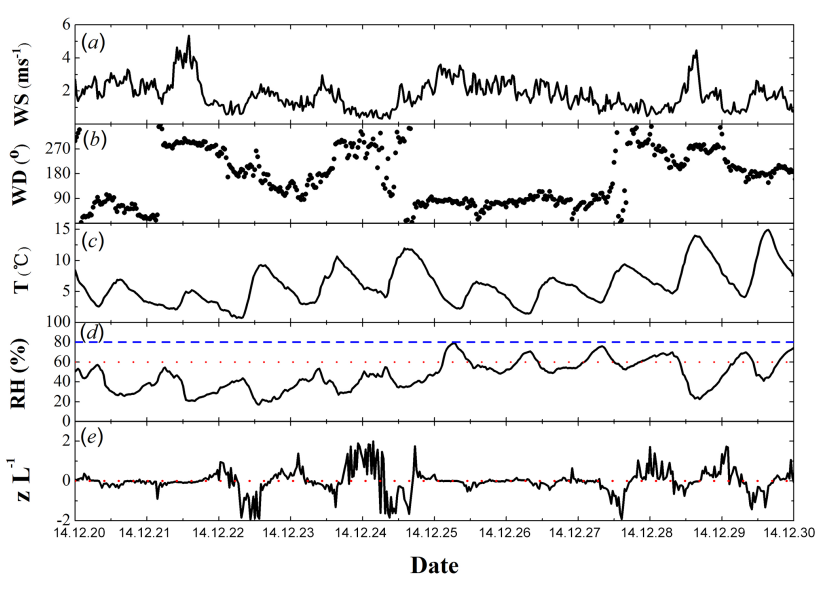

Figure 2. Temporal variations in the (a) wind speed, (b) wind direction, (c) air temperature, (d) relative humidity $(\mathrm{RH})$ and (e) dimensionless parameter $(z / L)$ observed during 20-29 December 2014. The dashed line in (c) denotes RH $80 \%$, and the dotted line in (c) denotes RH $60 \%$. The dotted line in (e) denotes $z / L=0$. Details can be found in the text.

path, and the top was $18 \mathrm{~m}$ above the reference plane. A Campbell CSAT3 anemometer (manufactured in Utah, USA) was mounted to the top of the tower at the same height as the light path. Three-dimensional velocities and temperature fluctuations were sampled and recorded at $10 \mathrm{~Hz}$ and can be processed to provide the sensible heat flux, momentum flux, and stability near the surface every $30 \mathrm{~min}$. The measurement data were used to obtain the dimensionless parameter $z / L$ in the surface layer. Sensors for wind speed, wind direction, temperature and humidity were mounted at three levels on the tower, the uppermost level of which was at the top of the tower. The meteorological data were sampled every minute, averaged and saved every $20 \mathrm{~min}$.

At site $P$ in Fig. 1a, approximately $3 \mathrm{~km}$ from the USTC experimental site, the mass concentrations and visibility data were measured at a height of $6 \mathrm{~m}$ above ground. The aerosol mass concentrations were recorded for $M_{\mathrm{a}}$ in Eq. (6) every hour. The visibility data were recorded every $10 \mathrm{~min}$ and averaged hourly.

The measurement period was from 20 to December 29 2014, a total of 10 days. The weather remained sunny during the experiment, and the typical properties of aerosol mass vertical transport were easy to determine.

\section{Experimental results}

To estimate the urban aerosol vertical transport flux, we measured the meteorological conditions, aerosol mass concentration, visibility, and real and imaginary parts of the AERISP. Finally, we calculated the aerosol mass flux.

\subsection{Meteorological conditions}

To better analyse the characteristics of aerosol vertical transport flux, we provided meteorological conditions during the experiment in Figs. 2a-e, including temperature, humidity, wind speed, wind direction and the dimensionless parameter $z / L$. Figure 2 a shows that $90 \%$ of the wind speed was less than $3 \mathrm{~m} \mathrm{~s}^{-1}$, and the maximum wind speed was $5.7 \mathrm{~m} \mathrm{~s}^{-1}$. As shown in Fig. 2b, all wind directions were detected, with easterly and westerly wind dominating. The statistical characteristics of wind speed and wind direction were near the annual mean distributions and are representative of the region. Figure $2 \mathrm{c}$ provides the temperature variation with time, showing clear diurnal variations. The highest air temperature was $14.9^{\circ} \mathrm{C}$, and the lowest air temperature was $0.76^{\circ} \mathrm{C}$. During the experimental period, it was warm compared to the local temperature climatology, while industrial production and other daily activities were normal. Figure $2 \mathrm{~d}$ shows the temporal variations in relative humidity. As we know, relative humidity is an important factor that controls aerosol particle growth (Flores et al., 2012; Winkler, 1973). Therefore, to study the transport flux of dry aerosol mass from different surface aerosol sources, only measurements with a relative humidity less than $60 \%$ were used in the analysis to minimize the influence of the water content in the aerosols. As shown in Fig. 2d, the relative humidity was less than $60 \%$ during most of the experiment and was less than $80 \%$ throughout the entire experiment. Figure $2 \mathrm{e}$ provides the dimensionless parameter $z / L$, which shows that the atmosphere was experiencing unstable stratification during the day and was stable during night. The turbulence during the unstable conditions in the surface layer significantly contributed to the vertical transport of heat, mass, and water vapour (Stull, 1988).

\subsection{Ratio of aerosol mass concentration to the imaginary part of the AERI}

$R_{\mathrm{MN}}$ in Eq. (6) is the ratio of the aerosol mass concentration to the imaginary part of the AERI. Theoretical analysis showed that $R_{\mathrm{MN}}$ is related to the refractive index, mass density of the aerosol particles, and aerosol particle size distribution. Figure 3 presents the temporal variations of mass concentration $\left(M_{\mathrm{a}}\right)$ and visibility $\left(L_{\mathrm{V}}\right)$ in the surface layer. The maximum $M_{\mathrm{a}}$ was $712 \mu \mathrm{g} \mathrm{m}^{-3}$, and the mean $M_{\mathrm{a}}$ was $67 \mu \mathrm{g} \mathrm{m}^{-3}$. The maximum visibility $\left(L_{\mathrm{V}}\right)$ was $31 \mathrm{~km}$, and the mean was $13 \mathrm{~km}$. The imaginary part of the AERI can be calculated from the visibility using Eq. (9) and is presented in Fig. 4 for measurements with a relative humidity less than $60 \%$. The scatter diagram of the imaginary part of the AERI $\left(n_{\mathrm{Im}}\right)$ and $M_{\mathrm{a}}$ given in Fig. 4 shows that there is a good correlation between them, with a linear correlation coefficient of 0.94. The linear fit given in Fig. 4 has a slope of $6216 \mathrm{~kg} \mathrm{~m}^{-3}$. Therefore, $R_{\mathrm{MN}}$ was set to $6216 \mathrm{~kg} \mathrm{~m}^{-3}$ in this study to estimate the aerosol vertical transportation flux. 

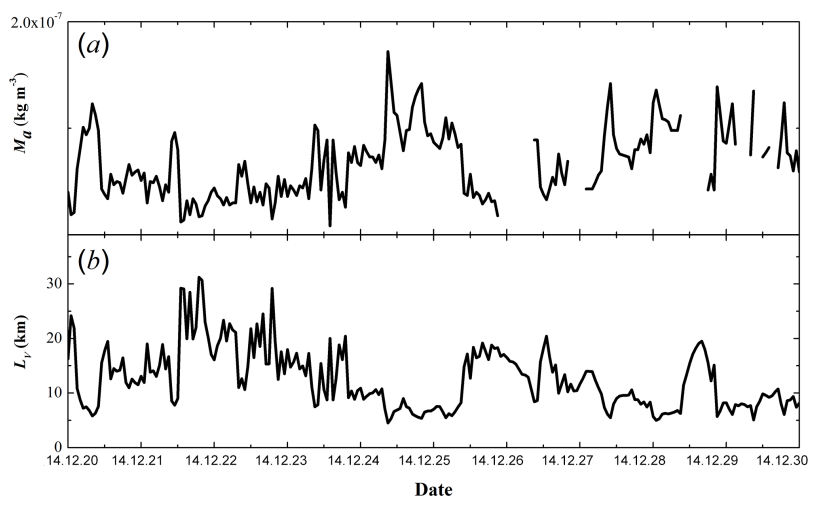

Figure 3. Temporal variations in the aerosol mass concentration $M_{\mathrm{a}}$ (a) and visibility $L_{\mathrm{V}}$ (b) observed during 20-29 December 2014.

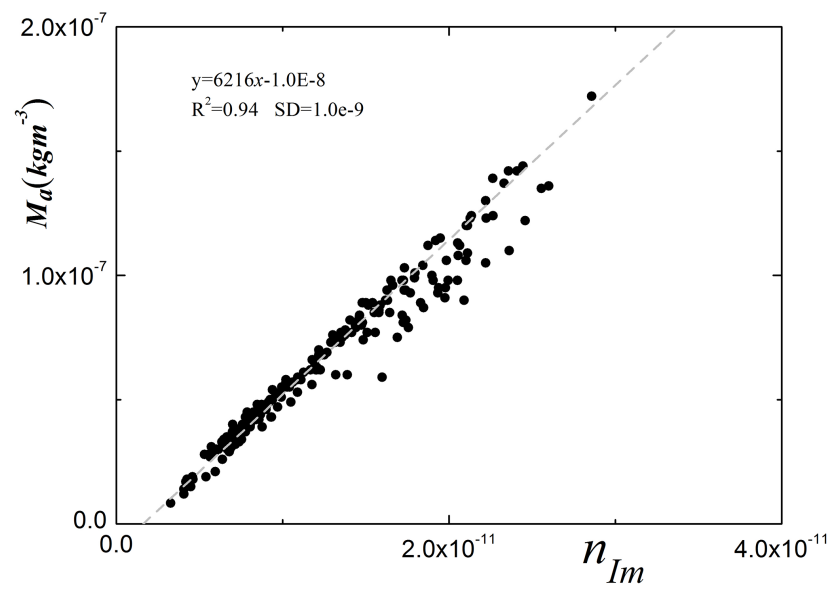

Figure 4. Scatterplots of aerosol mass concentration $M_{\mathrm{a}}$ vs. the imaginary part of AERI calculated from Fig. 3b by Eq. (12).

\subsection{Temperature structure parameter and the imaginary part of the AERISP}

To calculate the aerosol mass flux from Eq. (7), the temperature structure parameter and the imaginary part of the AERISP must be measured. The temperature structure parameter can be obtained by measuring the real part of the AERISP. Figure 5 shows the temporal variations of $C_{n, \mathrm{Re}}^{2}$ and $C_{n, \mathrm{Im}}^{2} . C_{n, \mathrm{Re}}^{2}$ in Fig. 5a exhibits a general diurnal variation (Stull, 1988), indicating that turbulence was strong during the day and weak during the night. $C_{n \text {.Im }}^{2}$ did not show the typical diurnal variation. The previous study showed that $C_{n, \mathrm{Im}}^{2}$ is related to both the turbulence strength and the pollution distribution (Yuan et al., 2015).

\subsection{Aerosol mass flux}

With the above-measured parameters, the aerosol mass flux can be calculated based on Eq. (7) and is presented in Fig. 6. The aerosol mass flux exhibited an obvious diurnal variation. The strong aerosol mass upward transport occurred at

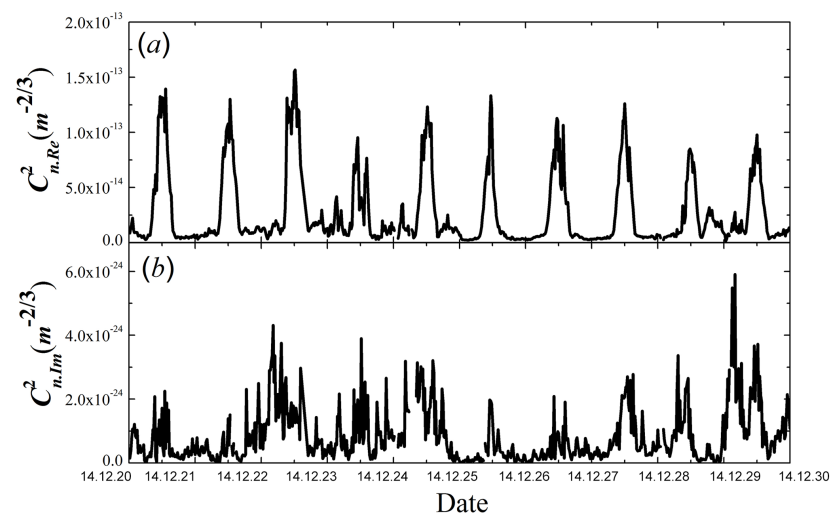

Figure 5. Temporal variations in the real part of the AERISP (a), and imaginary part of the AERISP (b) observed during 20-29 December 2014.

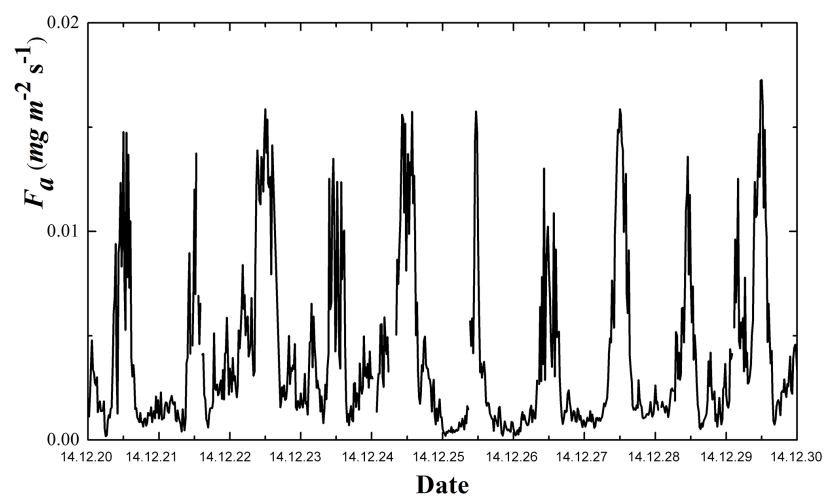

Figure 6. Temporal variations in the mass flux of aerosol observed during 20-29 December 2014.

noon, while the weak transport occurred during the night. The aerosol upward transport was also strong during the local traffic rush hours every day (06:00-9:00 and 17:0019:00), especially in the mornings of 22 and 29 December 2014, suggesting an increased number of vehicles on Monday mornings. During the experimental period, the mean value was $0.004 \mathrm{mg} \mathrm{m}^{-2} \mathrm{~s}^{-1}$ with a maximum aerosol mass flux of $0.017 \mathrm{mg} \mathrm{m}^{-2} \mathrm{~s}^{-1}$.

A comparison between $F_{\mathrm{a}}$ calculated by using the surface similarity theory (ST) with Eq. (6) and by using free convection approximation (abbreviated as FC) with Eq. (7) is shown in Fig. 7. According to Lagouarde et al. (2006), stability can be classified as $z / L<-0.15,-0.15<z / L<0$ and $z / L>0$ for unstable, weakly unstable and stable conditions, respectively. The comparison shows that scattering was a little large under stable and weakly unstable conditions, and the relative errors were 31 and $21 \%$, respectively. A good agreement was shown under unstable conditions with the relative error about $5 \%$. All of the data together gave a relative error of approximately $8 \%$ with a coefficient of determination (or $R^{2}$ ) of 0.92 . The overall small error indicates that 


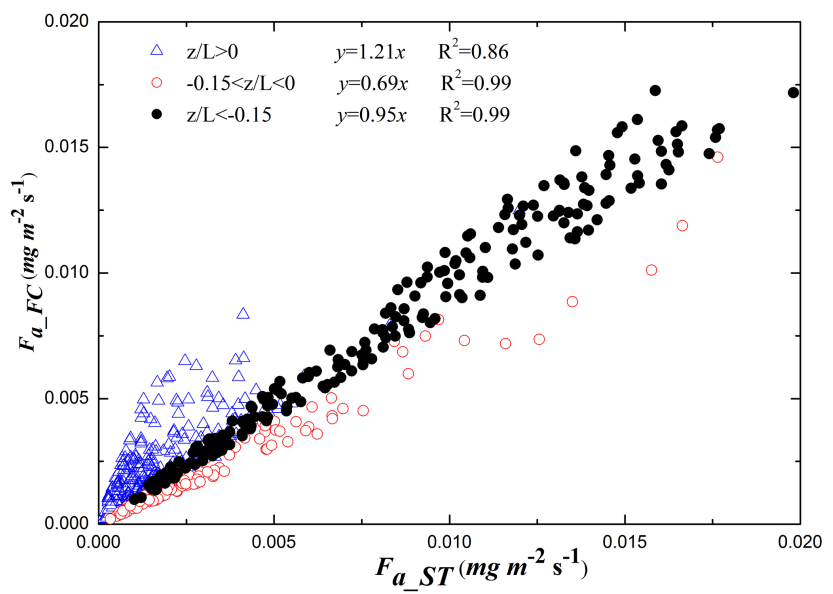

Figure 7. Comparison of aerosol mass fluxed based on the basis of similarity theory (ST) and the free convection (FC) approximation under three different stability conditions $(z / L<-0.15$, $-0.15<z / L<0$ and $z / L>0)$.

Eq. (7) for FC approximation is very attractive from a practical point of view because it allows one to compute the flux without needing any extra meteorological measurements. For the LAS for heat flux, the sign for the heat flux should be determined (Samain et al., 2012), but for our LAS measurements, the aerosol mass flux was always upward because the aerosol source was at the surface.

Although there are no direct measurements for aerosol mass flux for comparison, the aerosol mass flux measurements can be compared to the aerosol particle number flux using the EC method with a few assumptions. Järvi et al. (2009) measured the aerosol particle number flux from July 2007 to July 2008 near a road in Helsinki, Finland. The main pollution source in Helsinki is vehicle emissions. According to Fig. 5 in their paper, the maximum aerosol particle number flux was approximately $663 \times 10^{6} \mathrm{~m}^{-2} \mathrm{~s}^{-1}$ and occurred at noon in the urban areas during the winter season as well. It is reasonable to assume that urban aerosol is mainly composed of fine particles, and the aerosol particle volume distribution can be described by lognormal distributions with a median diameter of $0.3 \mu \mathrm{m}$ and geometric standard deviation of 1.7 (Dubovik et al., 2002). Furthermore, assuming that the mass density of aerosol particles is $1.46 \times 10^{3} \mathrm{~kg} \mathrm{~m}^{-3}$ (Yin et al., 2015), Järvi et al. (2009) observed a maximum aerosol particle number flux that corresponded to a maximum aerosol mass flux of approximately $0.0092 \mathrm{mg} \mathrm{m}^{-2} \mathrm{~s}^{-1}$. Although this was approximately half the maximum mass flux observed in Hefei City, the two measurements are comparable considering that Hefei City is much more polluted than Helsinki most of the time. Although this was not a side-by-side comparison, it indicated that the new method presented here was reasonable.

\section{Conclusion and discussion}

Based on the similarity theory and the light-propagation theory, a new method was developed to quantitatively estimate the aerosol mass flux in the urban surface layer. The similarity theory and light-propagation theory can be applied to aerosol transport in the surface layer, which required the aerosol particles to be small enough to follow the movement of air and the size distribution of the aerosol particles to remain unchanged. For aerosols with a residence life in the boundary layer longer than 1 hour, this requirement was well satisfied. Although there are coarse particles in the source regions (Dubovik et al., 2002), they typically fall out quickly.

The estimations for the aerosol mass flux by the proposed method require experimental measurements of the following parameters: the temperature structure parameter, the imaginary part of the AERISP and the ratio of the aerosol mass concentration to the imaginary part of the AERI. According to the 10-day measurements, the aerosol mass vertical transport flux showed the typical diurnal variation. During the experimental period, it was mainly sunny. Thus, the convective turbulence greatly contributed to the aerosol mass flux and resulted in a large aerosol mass flux during the day. Moreover, the aerosol mass flux was higher during local traffic rush hours. The measurement site was in Hefei City. The city has a population of approximately 3500000 and more than 600000 vehicles. Thus, vehicle emissions provide one of the main pollution sources. Our results indicated that the vertical transport flux of aerosol mass was controlled by both the turbulence transport and aerosol emissions, which was physically expected.

Although there were no other direct measurements available for comparison, the measurements were indirectly compared to the aerosol particle number flux measured by the EC method at another location, which revealed a comparable maximum mass flux. In the near future, we will explore sideby-side comparisons. Compared to the EC method, measuring aerosol mass flux with the light-propagation method had some advantages, such as no need to build a high tower and offering a large spatial coverage.

The error in the aerosol mass flux measurements resulted from theory and the instruments. Similar to the LAS for measuring sensible heat flux at the surface layer, instrument measurement error may be attributed to electronic or optical problems, which include a poor focal alignment of the receiver detector and the transmitter diode, calibration of electronics, and the effective diameter of the LAS transmitter and receiver (Moene et al., 2009; Kleissl et al., 2008, 2009). These errors can be minimized through careful experiment setup and data quality control. Theoretical error sources come from the invalidity of the surface-layer similarity theory under certain conditions, the occurrence of significant large aerosol particles, and the variations of between $n_{\operatorname{Im}}$ and $M_{\mathrm{a}}$ relationship. Under neutral and stable conditions, the sensible heat flux is difficult to assess with a LAS (Pauwels et 
al., 2008; Samain et al., 2012). Unlike the sensible heat flux, the aerosol source is often at the surface, and the aerosol vertical transport flux under the stable condition was very weak. Measurement results were in accordance with fact. Thus, lacking accurate aerosol vertical transport flux under the stable condition did not introduce significant error in overall aerosol mass flux estimations. The ratio of the aerosol mass concentration to the imaginary part of the AERI was assumed to be constant, which is a reasonably good assumption for a given location with a dominant aerosol type, such as urban aerosols. However, the variations in the ratio $R_{\mathrm{MN}}$ will introduce errors into the aerosol mass flux measurements. The ratio $R_{\mathrm{MN}}$ depends on the refractive index and size distribution of aerosol particles. Therefore, the ratio can be determined locally when the approach is applied to different locations. Of course, if there are some variations in the aerosol particle refractive index and particle size distribution, $R_{\mathrm{MN}}$ can be obtained by simultaneously measuring $M_{\mathrm{a}}$ and the imaginary part of the AERI, so that real-time $R_{\mathrm{MN}}$ can be obtained. The large aerosol particles cannot follow the movement of air well (Seinfeld and Pandis, 2006; Vogt et al., 2011a), which is one of the error sources for aerosol mass flux measurements. However, these large aerosols fall out very quickly and have a small impact on estimated aerosols, which can stay in the atmosphere for a day. All of these error estimations should be discussed quantitatively in the future. 
Appendix A: Atmospheric equivalent refractive index (AERI) and aerosol mass concentration

When the gases and aerosol particles in the atmosphere are considered as a whole, the AERI $n_{\text {eff }}$ can be written as follows (van de Hulst, 1957; Barrera et al., 2007; Calhoun et al., 2010):

$n_{\mathrm{eff}}=n_{\mathrm{m}}+\frac{i}{k} \frac{2 \pi}{\left(n_{\mathrm{m}} k\right)^{2}} \int_{0}^{\infty} S(0) \frac{\mathrm{d} N}{\mathrm{~d} D} \mathrm{~d} D$.

Equation (A1) includes two parts. The first is the contribution of air molecules, where $n_{\mathrm{m}}$ is the air refractive index. The second represents the scattering and absorption of aerosol particles, where $k$ is the light wave number $(k=2 \pi / \lambda$, where $\lambda$ is the work wavelength) and $i$ is an imaginary number. $S(0)$ is the aerosol forward scattering function ( 0 in the parentheses represents the scattering angle of zero), which can be calculated from the Mie scattering theory. $N$ is the number of aerosol particles per unit volume, $D$ is the aerosol diameter, and $\mathrm{d} N / \mathrm{d} D$ is the size distribution function of the aerosol particles.

For the atmosphere transparent band, the absorption of gases can be ignored because the extinction caused by molecular scattering is relatively small compared with that caused by atmospheric aerosols in the urban area. Therefore, there is only the real part of the refractive index of air in Eq. (A1). The real and imaginary parts of the AERI $\left(n_{\mathrm{Re}}\right.$ and $n_{\mathrm{Im}}$, $\left.n_{\mathrm{eff}}=n_{\mathrm{Re}}+i \cdot n_{\mathrm{Im}}\right)$ can then be derived as

$n_{\mathrm{Re}}=n_{\mathrm{m}}-\frac{1}{k} \frac{2 \pi}{\left(n_{\mathrm{m}} k\right)^{2}} \int_{0}^{\infty} \operatorname{Im}[S(0)] \frac{\mathrm{d} N}{\mathrm{~d} D} \mathrm{~d} D$

$n_{\mathrm{Im}}=\frac{1}{k} \frac{2 \pi}{\left(n_{\mathrm{m}} k\right)^{2}} \int_{0}^{\infty} \operatorname{Re}[S(0)] \frac{\mathrm{d} N}{\mathrm{~d} D} \mathrm{~d} D$.

As shown in Eqs. (A2)-(A3), $n_{\mathrm{Re}}$ is determined by the refractive index of air, the imaginary part of the forward scattering function of aerosol particles, and the distribution ofthe aerosol particles. $n_{\mathrm{Im}}$ is determined by the real part of the forward scattering function of aerosol particles and the distribution of the aerosol particles. According to the magnitude comparisons and the variation ranges of the two terms in Eq. (A2), $n_{\mathrm{Re}}$ is mainly determined by the refractive index of air (Liou, 2002; Tatarskii, 1961). Thus, the second term on the right-hand side of Eq. (A2) can be ignored.

According to the theory of small particle scattering (Liou, 2002), the extinction cross section of one particle is given by (Eq. (5.2.92) in Page 189 in Liou's book),

$\sigma_{e}=\frac{4 \pi}{k^{2}} \operatorname{Re}[S(0)]$.

So, for aerosols with a size distribution of $\mathrm{d} N / \mathrm{d} D$, the total extinction coefficient is

$\beta_{\mathrm{e}}=\frac{4 \pi}{k^{2}} \int_{0}^{\infty} \operatorname{Re}[S(0)] \frac{\mathrm{d} N}{\mathrm{~d} D} \mathrm{~d} D$.

A comparison between Eqs. (A3) and (A5) shows that there is a relationship between $n_{\mathrm{Im}}$ and the aerosol extinction coefficient $\left(\beta_{\mathrm{e}}\right)$, i.e. $n_{\mathrm{Im}}=\lambda \beta_{\mathrm{e}} / 4 \pi$ (Liou, 2002). Thus, the variable $n_{\mathrm{Im}}$ in Eq. (8) corresponds to the extinction, which is the sum of the contributions of scattering and absorption.

The aim of analysing the imaginary parts of the AERI $\left(n_{\mathrm{Im}}\right)$ is to obtain information about the aerosol mass concentration. The mass concentration of aerosols, $M_{\mathrm{a}}$, can be expressed as

$M_{\mathrm{a}}=\rho \frac{1}{6} \pi \int_{0}^{\infty} D^{3} \frac{\mathrm{d} N}{\mathrm{~d} D} \mathrm{~d} D$,

where $\rho$ is the mass density of the aerosol particles. 
Acknowledgements. This study was funded by the National Natural Science Foundation of China (41475012) and partially by the Jiangsu Provincial Collaborative Innovation Centre of Climate Change. We also thank two anonymous reviewers for their constructive and helpful comments.

Edited by: P. Xie

\section{References}

Barrera, R. G., Reyes-Coronado, A., and Garcia-Valenzuela, A.: Nonlocal nature of the electrodynamic response of colloidal systems, Phys. Rev. B, 75, 184202, doi:10.1103/PhysRevB.75.184202, 2007.

Bond, T. C., Streets, D. G., Yarber, K. F., Nelson, S. M., Woo, J. H., and Klimont, Z.: A technology-based global inventory of black and organic carbon emissions from combustion, J. Geophys. ResAtmos., 109, D14203, doi:10.1029/2003jd003697, 2004.

Brooks, I., Yelland, M. J., Upstill-Goddard, R. C., Nightingale, P. D., Archer, S., d'Asaro, E., Beale, R., Beatty, C., Blomquist, B., Bloom, A. A., Brooks, B. J., Cluderay, J., Coles, D., Dacey, J., DeGrandpre, M., Dixon, J., Drennan, W. M., Gabriele, J., Goldson, L., Hardman-Mountford, N., Hill, M. K., Horn, M., Hsueh, P.-C., Huebert, B., de Leeuw, G., Leighton, T. G., Liddicoat, M., Lingard, J. J. N., McNeil, C., McQuaid, J. B., Moat, B. I., Moore, G., Neill, C., Norris, S. J., O’Doherty, S., Pascal, R. W., Prytherch, J., Rebozo, M., Sahlee, E., Salter, M., Schuster, U., Skjelvan, I., Slagter, H., Smith, M. H., Smith, P. D., Srokosz, M., Stephens, J. A., Taylor, P. K., Telszewski, M., Walsh, R., Ward, B., Woolf, D. K., Young, D., and Zemmelink, H.: Physical Exchanges at the Air-Sea Interface: UK-SOLAS Field Measurements, B. Am. Meteorol. Soc., 90, 629-644, 2009.

Cachorro, V. E. and Tanre, D.: The correlation between particle mass loading and extinction: Application to desert dust aerosol content estimation, Remote Sens. Environ., 60, 187-194, doi:10.1016/s0034-4257(96)00185-x, 1997.

Calhoun, W. R., Maeta, H., Combs, A., Bali, L. M., and Bali, S.: Measurement of the refractive index of highly turbid media, Opt. Lett., 35, 1224-1226, 2010.

Chang, S.-C. and Lee, C.-T.: Evaluation of the trend of air quality in Taipei, Taiwan from 1994 to 2003, Environ. Monit. Assess., 127, 87-96, doi:10.1007/s10661-006-9262-1, 2007.

Chen, J., Wang, J., and Mitsuaki, Y.: An independent method to determine the surface roughness length, Chin. J. Atmos. Sci., 17, 21-26, 1993 (in Chinese with English abstact).

Chin, M., Kahn, R. A., and Schwartz, S. E.: Atmospheric Aerosol Properties and Climate Impacts, US Climate Change Science Program, 115 pp., 2009.

Cruz, A. M. J., Sarmento, S., Almeida, S. M., Silva, A. V., Alves, C., Freitas, M. C., and Wolterbeek, H.: Association between atmospheric pollutants and hospital admissions in Lisbon, Environ. Sci. Pollut. R., 22, 5500-5510, doi:10.1007/s11356-014-3838-z, 2015.

DeBruin, H. A. R., vandenHurk, B., and Kohsiek, W.: The scintillation method tested over a dry vineyard area, Bound.-Lay. Meteorol., 76, 25-40, 1995.

Dubovik, O., Holben, B., Eck, T. F., Smirnov, A., Kaufman, Y. J., King, M. D., Tanre, D., and Slutsker, I.: Variability of absorption and optical properties of key aerosol types observed in worldwide locations, J. Atmos. Sci., 59, 590-608, doi:10.1175/15200469(2002)059<0590:voaaop>2.0.co;2, 2002.

Evans, J. G. and De Bruin, H. A. R.: The Effective Height of a TwoWavelength Scintillometer System, Bound-Lay. Meteorol., 141, 165-177, doi:10.1007/s10546-011-9634-0, 2011.

Flores, M. J., Bar-Or, R. Z., Bluvshtein, N., Abo-Riziq, A., Kostinski, A., Borrmann, S., Koren, I., Koren, I., and Rudich, Y.: Absorbing aerosols at high relative humidity: linking hygroscopic growth to optical properties, Atmos. Chem. Phys., 12, 55115521, doi:10.5194/acp-12-5511-2012, 2012.

Gebicki, J. and Szymanska, K.: Comparative field test for measurement of PM10 dust in atmospheric air using gravimetric (reference) method and beta-absorption method (Eberline FH 62-1), Atmos. Environ., 54, 18-24, doi:10.1016/j.atmosenv.2012.02.068, 2012.

Harrison, R. M., Dall'Osto, M., Beddows, D. C. S., Thorpe, A. J., Bloss, W. J., Allan, J. D., Coe, H., Dorsey, J. R., Gallagher, M., Martin, C., Whitehead, J., Williams, P. I., Jones, R. L., Langridge, J. M., Benton, A. K., Ball, S. M., Langford, B., Hewitt, C. N., Davison, B., Martin, D., Petersson, K. F., Henshaw, S. J., White, I. R., Shallcross, D. E., Barlow, J. F., Dunbar, T., Davies, F., Nemitz, E., Phillips, G. J., Helfter, C., Di Marco, C. F., and Smith, S.: Atmospheric chemistry and physics in the atmosphere of a developed megacity (London): an overview of the REPARTEE experiment and its conclusions, Atmos. Chem. Phys., 12, 3065-3114, doi:10.5194/acp-12-3065-2012, 2012.

Hartogensis, O. K., Watts, C. J., Rodriguez, J. C., and De Bruin, H. A. R.: Derivation of an effective height for scintillometers: La Poza experiment in Northwest Mexico, J. Hydrometeorol., 4, 915-928, doi:10.1175/15257541(2003)004<0915:doaehf>2.0.co;2, 2003.

Hill, R. J.: Spectra of fluctuations in refractivity, temperature, humidity, and the temperature-humidity co-spectrum in the inertial and dissipation ranges, Radio Sci., 13, 953-961, doi:10.1029/RS013i006p00953, 1978.

IPCC: Climate change 2007: Impacts, adaptation and vulnerability, Report of the Intergovernmental Panel on Climate Change, edited by: Parry, M. L., Canziani, O. F., Palutikof, J. P., van der Linden, P. J., and Hanson, C. E., Cambridge University Press, Cambridge, UK and New York, NY, USA, 976 pp., 2007.

IPCC: Climate Change 2014: Synthesis Report, Contribution of Working Groups I, II and III to the Fifth Assessment Report of the Intergovernmental Panel on Climate Change, edited by: Core Writing Team, Pachauri, R. K. and Meyer, L., IPCC, Geneva, Switzerland,, 151 pp., 2014.

Järvi, L., Rannik, Ü., Mammarella, I., Sogachev, A., Aalto, P. P., Keronen, P., Siivola, E., Kulmala, M., and Vesala, T.: Annual particle flux observations over a heterogeneous urban area, Atmos. Chem. Phys., 9, 7847-7856, doi:10.5194/acp-9-7847-2009, 2009.

Jennings, S. G., Pinnick, R. G., and Auvermann, H. J.: Effects of particulate complex refractive-index and particle-size distribution variations on atmospheric extinction and absorption for visible through middle ir wavelengths, Appl. Opt., 17, 3922-3929, doi:10.1364/ao.17.003922, 1978.

Jennings, S. G., Pinnick, R. G., and Gillespie, J. B.: Relation between absorption-coefficient and imaginary index of at- 
mospheric aerosol constituents, Appl. Opt., 18, 1368-1371, doi:10.1364/ao.18.001368, 1979.

Kaimal, J. C., Izumi, Y., Wyngaard, J. C., and Cote, R.: Spectral characteristics of surface-layer turbulence, Q. J. Roy. Meteor. Soc., 98, 563-589, 1972.

Kanakidou, M., Seinfeld, J. H., Pandis, S. N., Barnes, I., Dentener, F. J., Facchini, M. C., Van Dingenen, R., Ervens, B., Nenes, A., Nielsen, C. J., Swietlicki, E., Putaud, J. P., Balkanski, Y., Fuzzi, S., Horth, J., Moortgat, G. K., Winterhalter, R., Myhre, C. E. L., Tsigaridis, K., Vignati, E., Stephanou, E. G., and Wilson, J.: Organic aerosol and global climate modelling: a review, Atmos. Chem. Phys., 5, 1053-1123, doi:10.5194/acp-5-1053-2005, 2005.

Kipp and Zonen: Las \& X-Las Instruction manual, Kipp \& Zonen, Delft, the Netherlands, 74 pp., 2007.

Kleissl, J., Gomez, J., Hong, S. H., Hendrickx, J. M. H., Rahn, T., and Defoor, W. L.: Large aperture scintillometer intercomparison study, Bound-Lay. Meteorol., 128, 133-150, doi:10.1007/s10546-008-9274-1, 2008.

Kleissl, J., Watts, C. J., Rodriguez, J. C., Naif, S., and Vivoni, E. R.: Scintillometer Intercomparison Study-Continued, BoundLay. Meteorol., 130, 437-443, doi:10.1007/s10546-009-9352-z, 2009.

Kondratyev, K. Y., Ivlev, L. S., Krapivin, V. F., and Varotsos, C. A.: Atmospheric aerosol properties Formation, process and impacts, Springer, Chichester, UK, 572 pp., 2006.

Koshiek, W.: Measuring $C_{\mathrm{T}}^{2}, C_{Q}^{2}$ and $C_{T Q}$ in the unstable surface layer, and relations to the vertical fluxes of heat and moisture, Bound.-Lay. Meteorol., 24, 89-107, 1982.

Lagouarde, J. P., Irvine, M., Bonnefond, J. M., Grimmond, C. S. B., Long, N., Oke, T. R., Salmond, J. A., and Offerle, B.: Monitoring the sensible heat flux over urban areas using large aperture scintillometry: Case study of Marseille city during the escompte experiment, Bound.-Lay. Meteorol., 118, 449-476, doi:10.1007/s10546-005-9001-0, 2006.

Lee, X.: Handbook of Micrometeorology, A Guide for Surface Flux Measurement and Analysis, edited by: Lee, X., Kluwer academic publishers, New York, USA, 250 pp., 2004.

Li, J., Wang, Z., Akimoto, H., Tang, J., and Uno, I.: Modeling of the impacts of China's anthropogenic pollutants on the surface ozone summer maximum on the northern Tibetan Plateau, Geophys. Res. Lett., 36, L24802, doi:10.1029/2009g1041123, 2009.

Li, P., Xin, J., Wang, Y., Li, G., Pan, X., Wang, S., Cheng, M., Wen, T., Wang, G., and Liu, Z.: Association between particulate matter and its chemical constituents of urban air pollution and daily mortality or morbidity in Beijing City, Environ. Sci. Pollut. R., 22, 358-368, doi:10.1007/s11356-014-3301-1, 2015.

Lighthart, B. and Shaffer, B. T.: Bacterial flux from chaparral into the atmosphere in mid-summer at a high desert location, Atmos. Environ., 28, 1267-1274, 1994.

Liou, K. N.: An Introduction to Atmospheric Radiation, 2nd Edition, Academic Press, CA, USA, 599 pp., 2002.

Mårtensson, E. M., Nilsson, E. D., Buzorius, G., and Johansson, C.: Eddy covariance measurements and parameterisation of traffic related particle emissions in an urban environment, Atmos. Chem. Phys., 6, 769-785, doi:10.5194/acp-6-769-2006, 2006.

Moene, A. F., Beyrich, F., and Hartogensis, O. K.: Developments in scintillometry, B. Am. Meteorol. Soc., 90, 694-698, doi:10.1175/2008bams2672.1, 2009.
Moosmueller, H., Chakrabarty, R. K., and Arnott, W. P.: Aerosol light absorption and its measurement: A review, J. Quant. Spectrosc. Ra., 110, 844-878, doi:10.1016/j.jqsrt.2009.02.035, 2009.

Myhre, G., Berglen, T. F., Johnsrud, M., Hoyle, C. R., Berntsen, T. K., Christopher, S. A., Fahey, D. W., Isaksen, I. S. A., Jones, T. A., Kahn, R. A., Loeb, N., Quinn, P., Remer, L., Schwarz, J. P., and Yttri, K. E.: Modelled radiative forcing of the direct aerosol effect with multi-observation evaluation, Atmos. Chem. Phys., 9, 1365-1392, doi:10.5194/acp-9-1365-2009, 2009.

Nakayama, T., Ikeda, Y., Sawada, Y., Setoguchi, Y., Ogawa, S., Kawana, K., Mochida, M., Ikemori, F., Matsumoto, K., and Matsumi, Y.: Properties of light-absorbing aerosols in the Nagoya urban area, Japan, in August 2011 and January 2012: Contributions of brown carbon and lensing effect, J. Geophys. Res-Atmos., 119, 12721-12739, doi:10.1002/2014jd021744, 2014.

Nemitz, E., Dorsey, J. R., Flynn, M. J., Gallagher, M. W., Hensen, A., Erisman, J.-W., Owen, S. M., Dämmgen, U., and Sutton, M. A.: Aerosol fluxes and particle growth above managed grassland, Biogeosciences, 6, 1627-1645, doi:10.5194/bg-6-16272009, 2009.

Obukhov, A. M.: Turbulence in an atmosphere with a non-uniform temperature, Bound-Lay. Meteorol., 2, 7-29, 1971.

Pauwels, V. R. N., Timmermans, W., and Loew, A.: Comparison of the estimated water and energy budgets of a large winter wheat field during AgriSAR 2006 by multiple sensors and models, J. Hydrol., 349, 425-440, doi:10.1016/j.jhydrol.2007.11.016, 2008.

Qiu, J. H., Yang, L. Q., and Zhang, X. Y.: Characteristics of the imaginary part and single-scattering albedo of urban aerosols in northern China, Tellus B., 56, 276-284, doi:10.1111/j.16000889.2004.00101.x, 2004.

Ripamonti, G., Jarvi, L., Molgaard, B., Hussein, T., Nordbo, A., and Hameri, K.: The effect of local sources on aerosol particle number size distribution, concentrations and fluxes in Helsinki, Finland, Tellus B., 65, 19786, doi:10.3402/tellusb.v65i0.19786, 2013.

Samain, B., Defloor, W., and Pauwels, V. R. N.: Continuous Time Series of Catchment-Averaged Sensible Heat Flux from a Large Aperture Scintillometer: Efficient Estimation of Stability Conditions and Importance of Fluxes under Stable Conditions, J. Hydrometeorol., 13, 423-442, doi:10.1175/jhm-d-11-030.1, 2012.

Seinfeld, J. H. and Pandis, S. N.: Atmospheric Chemisty and Physics,From Air Pollution to Climate Change, 2nd Edition ed., John Wily \& Sons, Inc, New York, USA, 1232 pp., 2006.

Solignac, P. A., Brut, A., Selves, J. L., Beteille, J. P., and GastelluEtchegorry, J. P.: Attenuating the Absorption Contribution on C-n2 Estimates with a Large-Aperture Scintillometer, BoundLay. Meteorol., 143, 261-283, doi:10.1007/s10546-011-9692-3, 2012.

Sproson, D. A. J., Brooks, I. M., and Norris, S. J.: The effect of hygroscopicity on eddy covariance estimates of sea-spray aerosol fluxes: a comparison of high-rate and bulk correction methods, Atmos. Meas. Tech., 6, 323-335, doi:10.5194/amt-6-323-2013, 2013.

Stull, R. B.: An Introduction to Boundary Layer Meteorology, Reidel Publishing Co., Dordrecht, the Netherlands, 666 pp., 1988.

Tatarskii, V. I.: Wave Propagation in a Turbulent Medium, McGrawHill Book Company Inc., New York, USA, 285 pp., 1961. 
van de Hulst, H. C.: Light Scattering by Small Particles, John Wiley \& Sons, Inc., New York, USA, 470 pp., 1957.

Vogt, M., Nilsson, E. D., Ahlm, L., Martensson, E. M., and Johansson, C.: Seasonal and diurnal cycles of $0.25-2.5 \mu \mathrm{m}$ aerosol fluxes over urban Stockholm, Sweden, Tellus B., 63, 935-951, doi:10.1111/j.1600-0889.2011.00551.x, 2011a.

Vogt, M., Nilsson, E. D., Ahlm, L., Mårtensson, E. M., and Johansson, C.: The relationship between $0.25-2.5 \mu \mathrm{m}$ aerosol and $\mathrm{CO}_{2}$ emissions over a city, Atmos. Chem. Phys., 11, 4851-4859, doi:10.5194/acp-11-4851-2011, 2011 b.

Wang, L., Gong, W., Xia, X., Zhu, J., Li, J., and Zhu, Z.: Longterm observations of aerosol optical properties at Wuhan, an urban site in Central China, Atmos. Environ., 101, 94-102, doi:10.1016/j.atmosenv.2014.11.021, 2015.

Wang, T., Jiang, F., Deng, J., Shen, Y., Fu, Q., Wang, Q., Fu, Y., Xu, J., and Zhang, D.: Urban air quality and regional haze weather forecast for Yangtze River Delta region, Atmos. Environ., 58, 7083, doi:10.1016/j.atmosenv.2012.01.014, 2012.

Wang, T. I., Ochs, G. R., and Clifford, S. F.: Saturation-resistant optical scintillometer to measure Cn2, J. Opt. Soc. Am., 68, 334338, 1978.

Wilson, D. K.: An alternative function for the wind and temperature gradients in unstable surface layers - Research note, Bound.-Lay. Meteorol., 99, 151-158, doi:10.1023/a:1018718707419, 2001.

Winkler, P.: The growth of atmospheric aerosol particles as a function of the relative humidity. II. An improved concept of mixed nuclei, J. Aerosol Sci., 4, 373-387, doi:10.1016/00218502(73)90027-x, 1973.

Wood, C. R., Jarvi, L., Kouznetsov, R. D., Nordbo, A., Joffre, S., Drebs, A., Vihma, T., Hirsikko, A., Suomi, I., Fortelius, C., O’Connor, E., Moiseev, D., Haapanala, S., Moilanen, J., Kangas, M., Karppinen, A., Vesala, T., and Kukkonen, J.: An overview of the urban boundary layer atmosphere network in helsinki, B. Am. Meteorol. Soc., 94, 1675-1690, doi:10.1175/bams-d-1200146.1, 2013.
Wu, Q., Zifa, W., Huansheng, C., Wen, Z., and Wenig, M.: An evaluation of air quality modeling over the pearl river delta during November 2006, Meteorol. Atmos. Phys., 116, 113-132, doi:10.1007/s00703-011-0179-z, 2012.

Wyngaard, J. C.: Turbulence in the Atmosphere, Cambridge University Press, New York, USA, 393 pp., 2010.

Wyngaard, J. C., Izumi, Y., and Collins, S. A.: Behavior of refractive-index-structure parameter near ground, J. Opt. Soc. Am., 61, 1646-1650, doi:10.1364/josa.61.001646, 1971.

Yin, Z., Ye, X., Jiang, S., Tao, Y., Shi, Y., Yang, X., and Chen, J.: Size-resolved effective density of urban aerosols in Shanghai, Atmos. Environ., 100, 133-140, doi:10.1016/j.atmosenv.2014.10.055, 2015.

Yuan, R., Luo, T., Sun, J., Zeng, Z., Ge, C., and Fu, Y.: A new method for measuring the imaginary part of the atmospheric refractive index structure parameter in the urban surface layer, Atmos. Chem. Phys., 15, 2521-2531, doi:10.5194/acp-15-25212015, 2015.

Zeweldi, D. A., Gebremichael, M., Wang, J., Sammis, T., Kleissl, J., and Miller, D.: Intercomparison of Sensible Heat Flux from Large Aperture Scintillometer and Eddy Covariance Methods: Field Experiment over a Homogeneous Semi-arid Region, Bound-Lay. Meteorol., 135, 151-159, doi:10.1007/s10546-0099460-9, 2010.

Zhao, B., Wang, P., Ma, J. Z., Zhu, S., Pozzer, A., and Li, W.: A high-resolution emission inventory of primary pollutants for the Huabei region, China, Atmos. Chem. Phys., 12, 481-501, doi:10.5194/acp-12-481-2012, 2012. 